\title{
Hypermethylation of the PTTG1IP promoter leads to low expression in early-stage non-small cell lung cancer
}

\author{
XIAOMING TAN ${ }^{1}$, SUFEN ZHANG $^{2}$, HUIFANG GAO $^{2}$, WANHONG HE ${ }^{2}$, \\ MINJIE XU ${ }^{2}$, QIHAN WU ${ }^{2}$, XIAOHUA NI ${ }^{2}$ and HANDONG JIANG ${ }^{1}$ \\ ${ }^{1}$ Department of Respiratory Disease, Renji Hospital, Shanghai Jiao Tong University School of Medicine, Shanghai 200127; \\ ${ }^{2}$ NHC Key Laboratory of Reproduction Regulation, Shanghai Institute of Planned Parenthood Research, \\ Fudan University, Shanghai 200032, P.R. China
}

Received May 22, 2018; Accepted April 15, 2019

DOI: $10.3892 / \mathrm{ol} .2019 .10400$

\begin{abstract}
Despite the clinical requirement for early diagnosis, the early events in lung cancer and their mechanisms are not fully understood. Pituitary tumor transforming gene 1 binding factor $(P T T G 1 I P)$ is a tumor-associated gene; however, to the best of our knowledge, its association with lung cancer has not been reported. The present study analyzed PTTGIIP expression in early-stage non-small cell lung cancer (NSCLC) samples and investigated its epigenetic regulatory mechanisms. The results revealed that the mRNA level of PTTGIIP in NSCLC tissues was significantly downregulated by $43 \%$ compared with that in adjacent tissues. In addition, overexpression of this gene significantly inhibited cell proliferation. According to data from The Cancer Genome Atlas, a significant negative correlation was identified between the PTTG1IP gene methylation level and expression level in lung adenocarcinoma and lung squamous cell carcinoma cases. Reduced representation bisulfite sequencing (RRBS) analysis of six paired early-stage NSCLC tissue samples indicated that the $\mathrm{CpG}$ island shore of the PTTGIIP promoter is hypermethylated in lung cancer tissues, which was further validated in 12 paired early-stage
\end{abstract}

Correspondence to: Dr Xiaohua Ni, NHC Key Laboratory of Reproduction Regulation, Shanghai Institute of Planned Parenthood Research, Fudan University, 2140 Xietu Road, Shanghai 200032, P.R. China

E-mail: xhni_sippr@163.com

Dr Handong Jiang, Department of Respiratory Disease, Renji Hospital, Shanghai Jiao Tong University School of Medicine, 1630 Dongfang Road, Pudong, Shanghai 200127, P.R. China E-mail: jianghd@163.com

Abbreviations: CT, computed tomography; NGS, next-generation sequencing; PTTG1IP, pituitary tumor transforming gene 1 binding factor; RRBS, reduced representation bisulfite sequencing; TCGA, The Cancer Genome Atlas; TSS, transcription start site

Key words: PTTGIIP, lung cancer, DNA methylation, expression, promoter
NSCLC samples via bisulfite amplicon sequencing. Following treatment with 5-aza-2'-deoxycytidine to reduce DNA methylation in the promoter region, the PTTGIIP mRNA level increased, indicating that the PTTGIIP promoter DNA methylation level negatively regulates $P T T G 1 I P$ transcription. In conclusion, in early-stage NSCLC, the PTTGIIP gene is regulated by DNA methylation in its promoter region, which may participate in the development and progression of lung cancer.

\section{Introduction}

Lung cancer, a complex disease involving both epigenetic and genetic changes, is the leading cause of cancer-associated mortality worldwide $(1,2)$. Lung cancer has had a high incidence rate and a poor 5-year survival rate of $<19 \%$ in the United States between 2006 and 2012 (2). One cause of the high mortality rate is the lack of specific early detection methods and the majority of patients are diagnosed with middle- or late-stage disease (3). Therefore, early detection and treatment strategies for lung cancer are urgently required.

Several imaging and cytology-based strategies have been utilized for early lung cancer detection. However, none have been demonstrated to completely reduce lung cancer mortality (3-5). Previous studies have reported that aberrant epigenetic changes are one of the most frequent cancer-associated events and are regarded as important mechanisms in carcinogenesis (6). Investigation of the associated molecular mechanisms can be exploited to diagnose early-stage lung cancer (3-5). Furthermore, methylation profiles may be potential biomarkers for early cancer diagnosis and they have been demonstrated to exhibit good prognostic value (4,7-9). Previously, accumulating evidence has confirmed that tumor tissues can be characterized by hypermethylation at promoter-associated $\mathrm{CpG}$ islands (CGIs) or global hypomethylation of the genome compared with normal tissues (9-11). Furthermore, certain studies have suggested that methylation of DNA CpG sites is an epigenetic regulator of gene expression that usually results in gene silencing $(12,13)$. Hao et al (12) reported that methylation patterns can predict prognosis and survival, and identified an association between differential methylation of $\mathrm{CpG}$ sites and the expression of cancer-associated genes. Their findings demonstrate the utility 
of methylation biomarkers for cancer molecular characterization, diagnosis and prognosis determination. Therefore, a number of specific tumor targets can be developed for use as DNA methylation-based biomarkers $(4,7,9)$.

At present, numerous useful cancer biomarkers have been identified. Pituitary tumor transforming gene 1 binding factor (PTTG1IP; also termed PBF) is a ubiquitously expressed proto-oncogene. PTTG1IP was first identified through its ability to bind to human securin, also termed pituitary tumor transforming gene (PTTG) $(14,15)$. Thus far, PTTG1IP has been reported to be highly expressed in thyroid, breast, colorectal, and liver cancer (16-19). However, to the best of our knowledge, its expression levels in lung cancer have not been reported. The present study investigated PTTGIIP expression in early non-small cell lung cancer (NSCLC) and examined the correlation between the PTTGIIP promoter region methylation level and the gene expression level.

\section{Materials and methods}

Tissue samples. In total, 18 pairs of early-stage (stage I or II) NSCLC tissues and adjacent tissues were obtained from the South Hospital of Renji Hospital Shanghai Jiao Tong University School of Medicine (Shanghai, China) between January 2014 and March 2015 (Table I). A total of 12 male and 6 female patients aged between 45 and 75 years were included in the present study. During excision surgery, $50 \mathrm{mg}$ fresh cancer tissue and $50 \mathrm{mg}$ adjacent normal tissue $(<2 \mathrm{~cm}$ from cancer margin) was obtained from each patient. Tissue samples were immediately frozen in liquid nitrogen following resection and stored at $-80^{\circ} \mathrm{C}$ until use. All included samples were histologically confirmed primary NSCLC and pathological stage I or II according to the Tumor-Node-Metastasis staging system (20). Written informed consent was obtained from all patients and the study was approved by the Ethics Committee of South Hospital of Renji Hospital Shanghai Jiao Tong University School of Medicine.

Cell culture and treatments. A549 cells of the human lung adenocarcinoma cell line were cultured in Roswell Park Memorial Institute-1640 medium (Thermo Fisher Scientific, Inc., Waltham, MA, USA) with $10 \%$ fetal bovine serum (FBS; Thermo Fisher Scientific, Inc., Waltham, MA, USA) and 1\% penicillin/streptomycin. MRC5 cells of the human embryonic lung fibroblast cell line were cultured in minimum essential medium (Thermo Fisher Scientific, Inc., Waltham, MA, USA) with $10 \%$ FBS and $1 \%$ penicillin/streptomycin. Cell cultures were incubated at $37^{\circ} \mathrm{C}$ in a humidified atmosphere with $5 \%$ $\mathrm{CO}_{2}$. Following A549 cell culture to $\sim 90 \%$ confluence, $1 \mu \mathrm{M}$ 5-aza-2'-deoxycytidine (5-aza-dC, Sigma-Aldrich; Merck KGaA, Darmstadt, Germany) was added to the culture medium. DMSO (Sigma-Aldrich; Merck KGaA) treatment was used as a control. The cells were harvested following 48-h treatment, and total RNA and genomic DNA were obtained according to standard protocols. In brief, TRIzol ${ }^{\circledR}$ reagent (Sigma-Aldrich; Merck KGaA, Darmstadt, Germany) was used for RNA extraction. Precipitated RNA was washed to remove impurities, and then resuspended for use in downstream applications. DNA extractions were performed using the High Pure PCR Template Preparation kit (Roche Diagnostics, Basel, Switzerland). Cells were lysed with Lysis Buffer and Proteinase $\mathrm{K}$, and released DNA was bound on a glass fiber filter and washed prior to elution.

Plasmid construction and cell transfection. To generate a vector expressing myc-PTTGIIP, the corresponding sequences were subcloned into a pcDNA3.1 vector (Invitrogen; Thermo Fisher Scientific, Inc., Waltham, MA, USA) that was subsequently termed pcDNA3.1/3Xmyc-PTTG1IP. Cells were plated the day prior to transfection and cultured to $70 \%$ confluence. Transfection was performed with Lipofectamine ${ }^{\circledR} 2000$ (Invitrogen; Thermo Fisher Scientific, Inc., Waltham, MA, USA) with $1 \mu \mathrm{g}$ plasmid/well, according to the manufacturer's protocol. Cells transfected with empty pcDNA3.1 vector was used as a control. The medium was replaced with new culture medium $6 \mathrm{~h}$ post-transfection. Cells were harvested $48 \mathrm{~h}$ following transfection and then prepared for subsequent assays.

Cell proliferation assay. Cell proliferation was assessed by Cell Counting Kit-8 (Dojindo Molecular Technologies, Inc., Kumamoto, Japan) assays. Cells were seeded at 1,000 cells/well into 96-well plates with $100 \mu \mathrm{l}$ culture medium. Subsequently, $10 \mu \mathrm{l} \mathrm{CCK}-8$ solution was added to the cells at every $24 \mathrm{~h}$ for 5 days and the cells were incubated for $2 \mathrm{~h}$ at $37^{\circ} \mathrm{C}$. The reaction product was quantified according to the manufacturer's protocol by measuring the absorbance at $450 \mathrm{~nm}$.

RNA and DNA extraction. Total RNA was extracted from cultured cells and tissue samples using TRIzol ${ }^{\circledR}$ reagent (Sigma-Aldrich; Merck KGaA, Darmstadt, Germany), according to the manufacturer's protocol. Genomic DNA was extracted from cultured cells and tissue samples using a High Pure PCR Template Preparation kit (Roche Diagnostics, Basel, Switzerland), according to the manufacturer's protocol.

Reverse transcription-quantitative polymerase chain reaction $(R T-q P C R)$. RT was performed with a mix of oligo dT primer and random primers for mRNA using a PrimeScript RT Reagent kit (Takara Biotechnology Co., Ltd., Dalian, China). qPCR was performed using a CFX96 Real-Time PCR detector (Bio-Rad Laboratories, Inc., Hercules, CA, USA) and SYBR Premix Ex Taq ${ }^{\mathrm{TM}}$ (Takara Biotechnology Co., Ltd., Dalian, China). The thermocycling conditions were: $95^{\circ} \mathrm{C}$ for $2 \mathrm{~min}$; 40 cycles of $95^{\circ} \mathrm{C}$ for $20 \mathrm{sec}, 60^{\circ} \mathrm{C}$ for $20 \mathrm{sec}$ and $72^{\circ} \mathrm{C}$ for $20 \mathrm{sec}$. The comparative $2^{-\Delta \Delta \mathrm{Cq}}$ method was used to calculate fold changes (21). GAPDH was used as an endogenous reference. The primers used for qPCR were as follows: PTTGIIP forward, 5'-GTCTGGACTACCCAGTTACAAGC-3' and reverse, 5'-CGCCTCAAAGTTCACCCA A-3'; GAPDH forward, 5'-GGAGTCCACTGGCGTCTTC-3' and reverse, 5'-GCTGATGATCTTGAGGCTGTTG-3'. The experiment was performed in triplicate.

Reduced representation bisulfite sequencing (RRBS). Genomic DNA was used to perform RRBS. RRBS library construction was performed as described previously (22). The library was sequenced on a next-generation sequencing (NGS) HiSeq platform (Illumina, Inc., San Diego, CA, USA). The sequencing data were aligned to a reference genome (UCSC 
Table I. Basic information of the paired lung cancer tissue and adjacent tissue samples.

\begin{tabular}{|c|c|c|c|}
\hline Sample no. & Sex & Diagnosis & Stage $^{\mathrm{d}}$ \\
\hline Pair $1^{c}$ & Female & Lung adenocarcinoma & II \\
\hline Pair $2^{a, c}$ & Male & Lung squamous cell carcinoma & II \\
\hline Pair $3^{a, c}$ & Female & Lung adenocarcinoma & II \\
\hline Pair $4^{\mathrm{a}, \mathrm{c}}$ & Male & Lung squamous cell carcinoma & II \\
\hline Pair $5^{a, c}$ & Male & Lung squamous cell carcinoma & II \\
\hline Pair $6^{\mathrm{a}, \mathrm{c}}$ & Female & Lung adenocarcinoma & $\mathrm{I}$ \\
\hline Pair $7^{\mathrm{a}, \mathrm{c}}$ & Male & Lung adenocarcinoma & II \\
\hline Pair $8^{a, c}$ & Female & Lung adenocarcinoma & II \\
\hline Pair $9^{a, c}$ & Male & Lung adenocarcinoma & II \\
\hline Pair $10^{\mathrm{a}, \mathrm{c}}$ & Male & Lung adenocarcinoma & II \\
\hline Pair $11^{\mathrm{a}, \mathrm{c}}$ & Male & Lung adenocarcinoma & II \\
\hline Pair $12^{c}$ & Male & Lung adenocarcinoma & $\mathrm{I}$ \\
\hline Pair $13^{\mathrm{b}}$ & Male & Lung adenocarcinoma & $\mathrm{I}$ \\
\hline Pair $14^{\mathrm{b}}$ & Male & Lung adenocarcinoma & II \\
\hline Pair $15^{\mathrm{b}}$ & Male & Lung squamous cell carcinoma & II \\
\hline Pair $16^{\mathrm{b}}$ & Female & Lung adenocarcinoma & $\mathrm{I}$ \\
\hline Pair $17^{b}$ & Male & Lung adenocarcinoma & I \\
\hline Pair $18^{\mathrm{b}}$ & Female & Lung adenocarcinoma & II \\
\hline
\end{tabular}

${ }^{\mathrm{a}}$ Analyzed by reverse transcription-quantitative polymerase chain reaction. ${ }^{\mathrm{b}}$ Analyzed by reduced representation bisulfite sequencing. ${ }^{\mathrm{c}}$ Analyzed by bisulfite amplicon sequencing. ${ }^{\mathrm{d}}$ According to the Tumor-Node-Metastasis staging system (20).

hg19) using Bismark (a flexible aligner and methylation caller for Bisulfite-Seq applications) with default parameters. The methylation level of each cytosine was calculated using the R package MethylKit (version 1.0.0; http://code.google. $\mathrm{com} / \mathrm{p} /$ methylkit), which is a comprehensive $\mathrm{R}$ package for analysis of genome-wide DNA methylation profiles (23).

Bisulfite amplicon sequencing. The DNA methylation level of the PTTG1IP promoter was analyzed in cells or tissue samples via bisulfite amplification followed by NGS. A total of $500 \mathrm{ng}$ DNA was bisulfite treated using an EZ DNA Methylation Gold-kit (Zymo Research Corp., Irvine, CA, USA). The bisulfite-converted DNA was used to amplify the candidate fragment with a Takara EX Taq Hot Start Version kit (Takara Biotechnology Co., Ltd., Dalian, China). The PCR products were loaded on a $1.5 \%$ agarose gel for analysis and recovered for library construction and NGS using a MiSeq platform (Illumina, Inc., San Diego, CA, USA). The DNA methylation level of candidate fragments was determined by analyzing the NGS data. The primers for amplification were as follows: PTTG1IP forward, 5'-GTATTGTTGAAGGGTGTAGAG ATG-3' and PTTGIIP reverse, 5'-CCACCCACCAAAACT TAATAATTA-3'.

Statistical analysis. The statistical significance of mean values in a two-sample comparison was determined with Student's t-test. $\mathrm{P}<0.05$ was considered to indicate a statistically significant difference. Data are presented as the mean \pm standard error. The lung adenocarcinoma and lung squamous cell carcinoma data sets from The Cancer Genome Atlas (TCGA) were used to further validate the relationship between promoter methylation and gene expression of PTTG1IP. Gene expression data (RNASeq) and DNA methylation data (Illumina methylation beadchip HM450 K) from 456 lung adenocarcinoma samples and 370 squamous cell carcinoma samples were downloaded from TCGA database on the cBioportal website (www.cbioportal.org). Spearman's non-parametric correlation test was performed to evaluate the correlation between gene methylation and expression using $\mathrm{R}$ software (version 3.3.2; http://www.R-project.org) (24).

\section{Results}

Decreased PTTGIIP expression in early-stage non-small cell lung cancer. Although PTTGIIP has been reported to be abnormally expressed in a variety of tumor types $(17-19,25)$, to the best of our knowledge, its association with lung cancer remains to be reported. The present study analyzed PTTGIIP expression in 10 paired early-stage NSCLC tissue samples (Table I). The RT-qPCR results revealed that PTTG1IP expression was decreased in all the cancer tissues except sample pair 10 (Fig. 1A). The mean mRNA level in the lung cancer tissues was significantly lower compared with that in the adjacent tissues (Fig. 1B). PTTG1IP expression was reduced by $80.1 \%$ in the lung cancer cell line A549 compared with the normal lung cell line MRC5 (Fig. 1C). To evaluate whether the expression level of PTTG1IP is associated with the proliferation capacity of lung cancer cells, PTTG1IP was overexpressed in A549 cells. The expression level of PTTGIIP was $\sim 11$ times higher in cells transfected with pcDNA3.1/3Xmyc-PTTG1IP compared with those transfected with empty pcDNA3.1 vector 2 days after transfection (Fig. 1D). A cell proliferation assay revealed that 
A

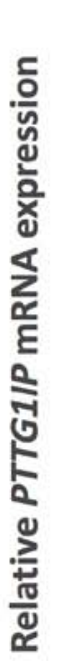

8

8

6

5

4

3

2

1

0

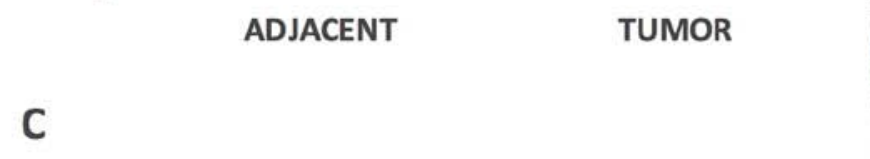

1.2

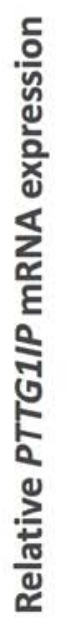

B

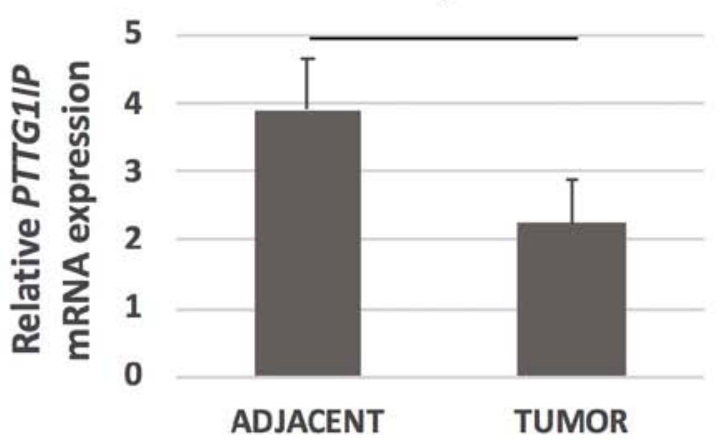

D

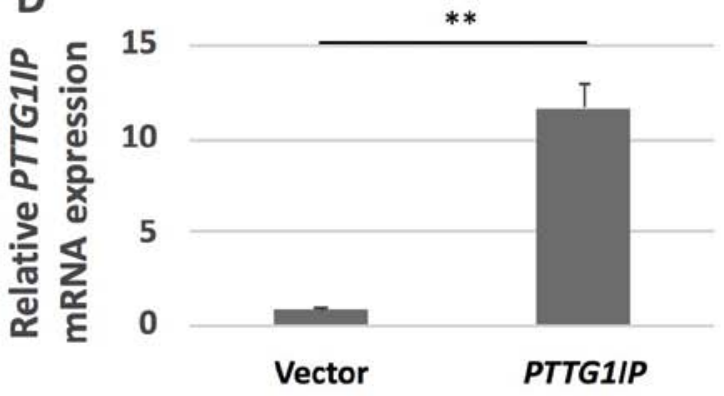

E

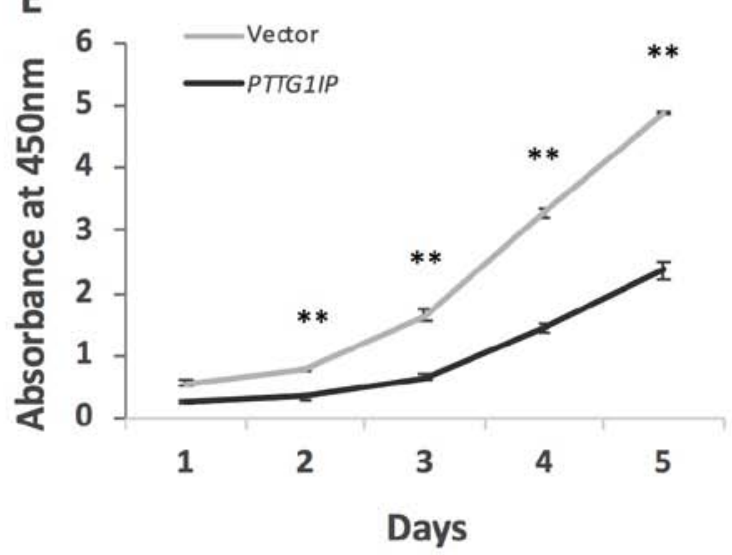

Figure 1.PTTG1IP expression is decreased in lung cancer and increased expression in a cancer cell line decreases cell proliferation. (A) The relative $P T T G 1 I P$ mRNA expression levels in paired early-stage lung cancer tissue samples. (B) The mean PTTG1IP expression levels in paired tissue samples. $\mathrm{P}<0.05$. (C) The relative PTTG1IP mRNA levels in normal lung cells (MRC5) and lung cancer cells (A549). ${ }^{* *} \mathrm{P}<0.01$. (D) $P$ TTG1IP overexpression was achieved in A549 cells. (E) The proliferation of PTTG1IP-overxpressing cells and control cells was determined by Cell Counting Kit- 8 assay at 24 h intervals over 5 days. Overexpression of PTTG1IP significantly decreased cell proliferation. ${ }^{*} \mathrm{P}<0.05,{ }^{* *} \mathrm{P}<0.01$ vs. $P T T G 1 I P$. Data are presented as the mean \pm standard error $(\mathrm{n}=3$ ). PTTG1IP, pituitary tumor transforming gene 1 binding factor.

the proliferation of pcDNA3.1/3Xmyc-PTTG1IP-transfected cells was significantly inhibited compared with the control cells. By day five, the number of transfected cells was $<50 \%$ of that in the control group (Fig. 1E).

DNA methylation analysis of the PTTGIIP promoter. To investigate the regulatory mechanism driving the decreased expression of PTTGIIP in lung cancer, the present study first downloaded RNAseq data and DNA methylation chip 450k data of lung adenocarcinoma and lung squamous cell carcinoma from The Cancer Genome Atlas (TCGA) database on the cBioportal website (www.cbioportal.org/). Correlation analysis revealed a significant negative correlation between the PTTGIIP gene methylation level and mRNA level in both lung adenocarcinoma and lung squamous cell carcinoma, with Spearman correlation coefficients of -0.415 and -0.457 , respectively (Fig. 2).

To further determine the association between PTTG1IP promoter methylation and gene expression, an RRBS study was conducted with six pairs of early-stage NSCLC tissue samples (Table I). As presented in Fig. 3, a plurality of CGIs were distributed among the 2,000 bp upstream and the 


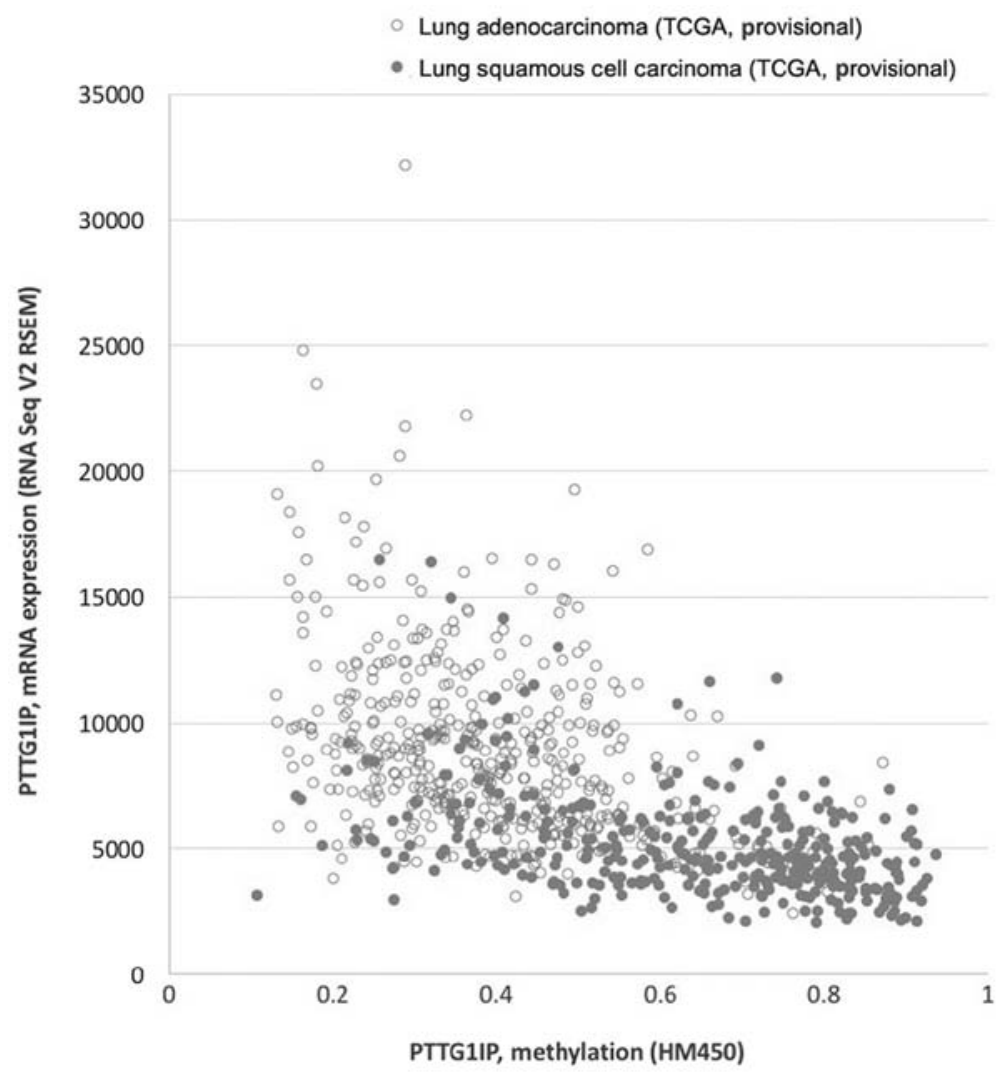

Figure 2. Expression level of PTTGIIP is correlated with the DNA methylation level in lung adenocarcinoma and lung squamous cell carcinoma. The expression level is presented as reads per kilobase of exon model per million mapped reads from RNAseq data in TCGA database. The DNA methylation level in each sample is presented as the mean methylation level of all CpG sites within the PTTGIIP gene body based on HumanMethylation450 BeadChip (HM450) data in TCGA database. TCGA, The Cancer Genome Atlas; PTTG1IP, pituitary tumor transforming gene 1 binding factor.

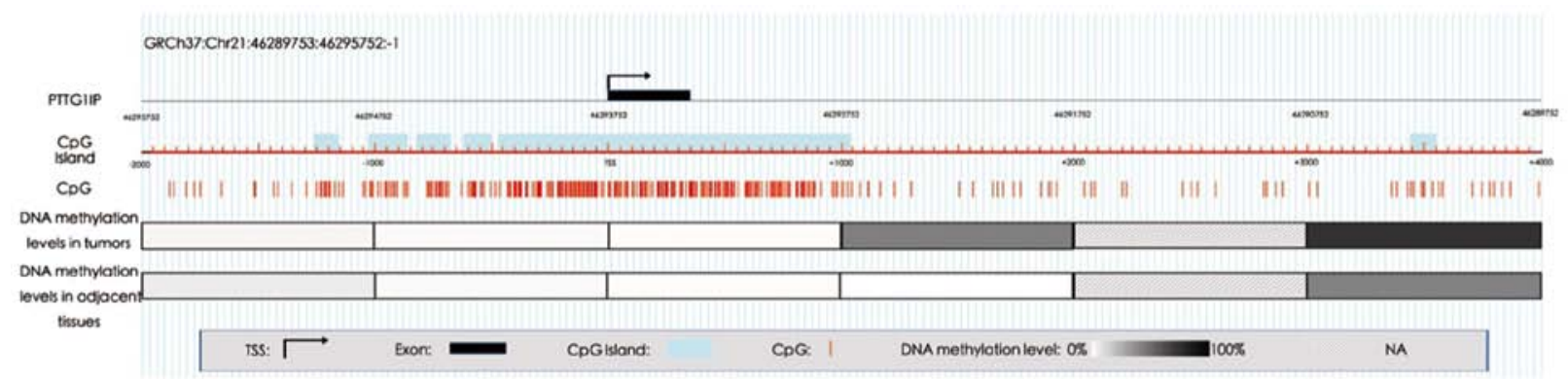

Figure 3. DNA hypermethylation is identified in the PTTG1IP promoter region. The location on chromosome 21 , the distribution of the CpG islands and CpG sites in the PTTG1IP promoter are listed in the top half of the figure. The DNA methylation levels in tumors and adjacent tissues based on reduced representation bisulfite sequencing analysis are presented in grayscale. Darker colors indicate higher levels of methylation. PTTG1IP, pituitary tumor transforming gene 1 binding factor; TSS, transcription start site.

2,000 bp downstream of the PTTGIIP transcription start site (TSS). However, regional DNA methylation analysis demonstrated that the region from $2,000 \mathrm{bp}$ upstream to $1,000 \mathrm{bp}$ downstream of the TSS was hypomethylated both in tumor tissues and adjacent tissues, although $\mathrm{CpG}$ loci were very concentrated in this region. However, a difference was identified in the CGI shore region of 1,000-2,000 bp downstream of the TSS between lung cancer tissues and adjacent tissues, with an mean DNA methylation difference of $50 \%$. In the region 5,000-6,000 bp downstream of the TSS, DNA was hypermethylated and the methylation level in cancer tissues was higher compared with that in adjacent tissues. Therefore, hypermethylation of the CGI shore region within the PTTGIIP gene promoter might be associated with its low expression.

DNA methylation level of the CGI shore region within the PTTG1IP gene promoter is associated with PTTGIIP expression. Subsequently, the methylation level of a fragment composed of four CG sites in the CGI shore region within the PTTGIIP promoter was measured in 12 pairs of early-stage NSCLC samples using bisulfite amplicon sequencing (Fig. 4A). Hypermethylation was identified in $>50 \%$ of the cancer tissues in the sample pairs. As presented in Fig. 4B, the mean methylation level of the four CG loci in tumor tissues was higher compared with that in adjacent 
A
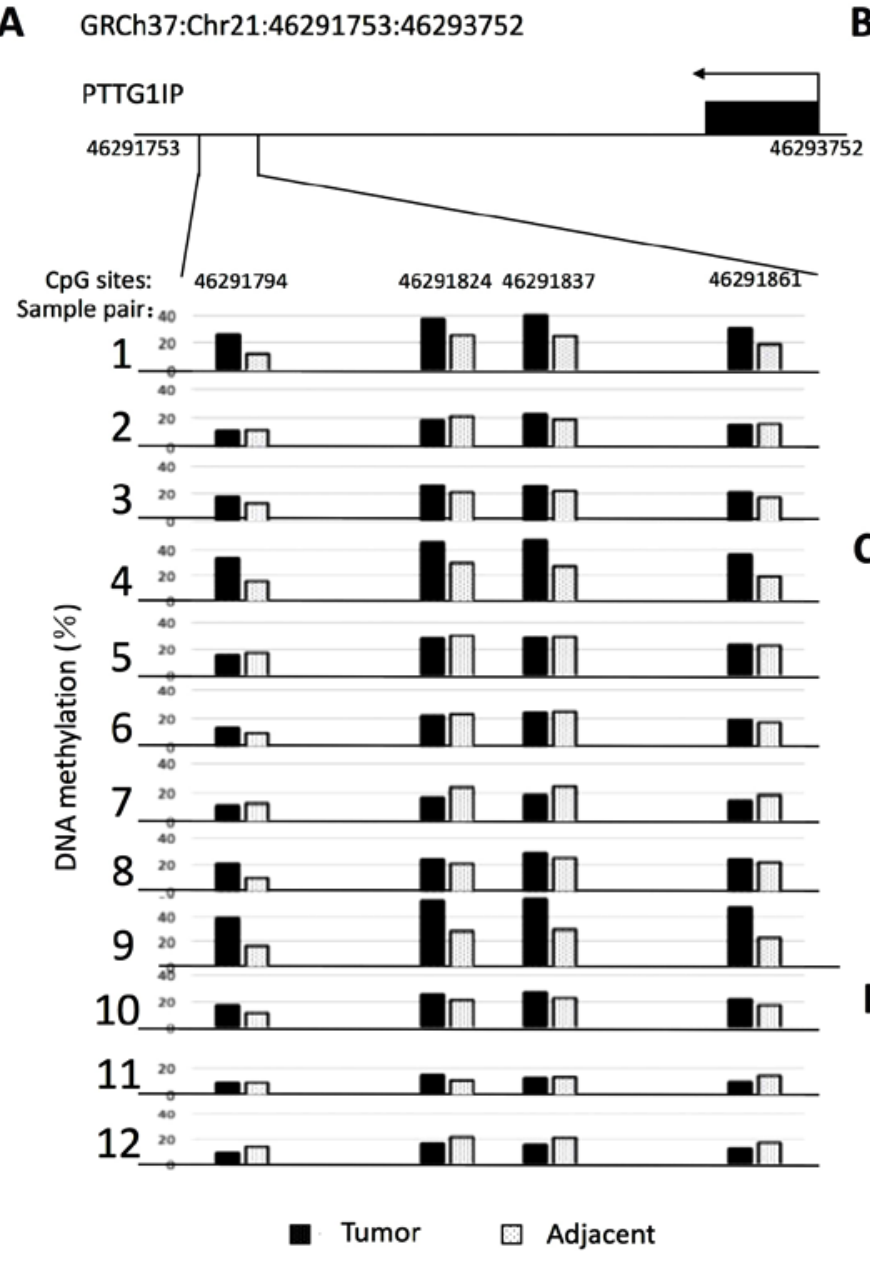

B

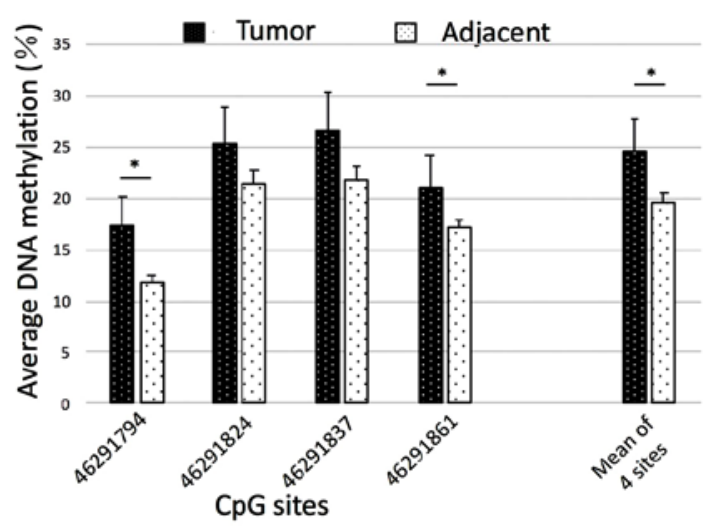

C

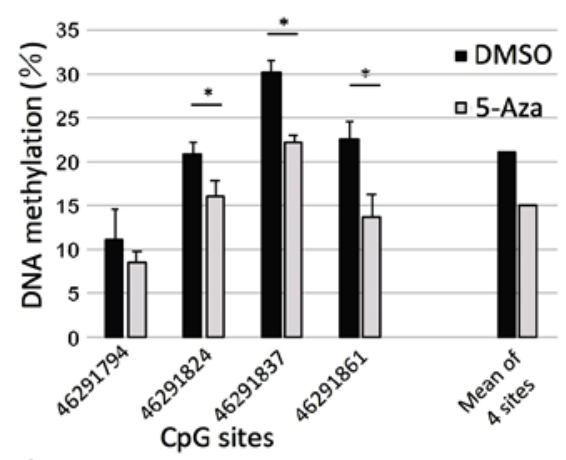

D

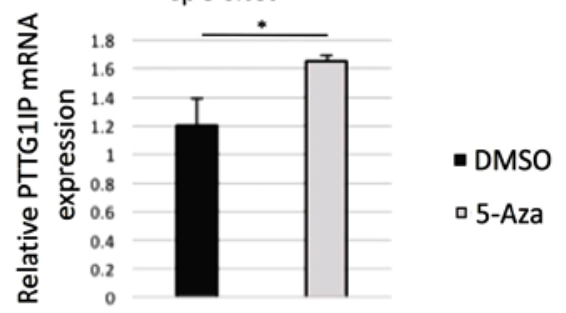

Figure 4. Validation of the hypermethylation in the PTTGIIP promoter region and its association with gene expression. (A) The methylation level of CpG sites in the PTTGIIP promoter in paired tumor samples based on bisulfite amplicon sequencing. (B) The mean methylation level of CpG sites in the PTTGIIP promoter in paired tumor samples. (C) The methylation level of CpG sites in the PTTG1IP promoter and (D) the expression level of PTTG1IP in A549 cells following treatment with $1 \mu \mathrm{m}$ 5-Aza. Data are presented as the mean \pm standard error ${ }^{*} \mathrm{P}<0.05$. PTTG1IP, pituitary tumor transforming gene 1 binding factor; 5-Aza, 5-aza-2'-deoxycytidine.

cancerous tissues. The mean methylation level of the four CG loci was 22.6 and $18.0 \%$, respectively, and the difference was significant. The trend of these results was consistent with that observed in the RRBS analysis. To verify the association between DNA methylation and gene expression in this region, A549 cells were treated with 5-aza-2'-deoxycytidine $(1 \mu \mathrm{M})$ to reduce DNA methylation levels. Following $48 \mathrm{~h}$ of treatment, a significant decrease in methylation of the three CG sites (except for site 46291794) was observed (Fig. 4C). The mean methylation level of the fragment was reduced from 21 to $15 \%$. Furthermore, RT-qPCR revealed that PTTGIIP gene expression was significantly increased following treatment with 5-aza-2'-deoxycytidine (Fig. 4D). These results suggest that hypermethylation in the CGI shore within the PTTGIIP promoter is essential for silencing of PTTGIIP.

\section{Discussion}

The present study reported a negative correlation between PTTGIIP gene expression and the methylation level of its promoter region in lung cancer. In addition, it was identified that PTTGIIP was highly methylated in the early stage of lung cancer and exhibited a low expression level. Cytological experiments indicated that PTTGIIP overexpression may inhibit lung cancer cell proliferation. The present study provides a possible new mechanism for lung cancer development and a potential novel marker for early diagnosis of lung cancer.

The National Lung Screening Trial demonstrated a 20\% reduction in lung cancer mortality using low-dose computed tomography (CT) screening (19). This survival benefit comes at the cost of testing numerous indeterminate pulmonary nodules, with an overall false-positive rate of $96.4 \%(26,27)$. One possible way to improve CT screening specificity is to use cancer-specific biomarkers from sputum and plasma. Previous studies have examined DNA methylation as a biomarker of cancer risk; however, the current low sensitivity and/or specificity of lung cancer screening is not sufficient (28-31). Epigenetic biomarkers, particularly DNA methylation, have become one of the most promising options for improving cancer diagnosis and have several advantages compared with other markers, including gene expression or genetic markers (32). 
One surprising finding in cancer biology that has emerged from TCGA sequencing projects is the wide diversity of mutations that promote cancer development (33). DNA methylation changes are covalent modifications that are very stable and usually occur early in carcinogenesis. In addition, DNA methylation can be detected by a variety of sensitive and low-cost techniques, even in samples with low tumor cell purity (32). This epigenetic modification can also be detected in different biological fluids and is one of the most promising noninvasive cancer detection tools (32).

Previously, different epigenetic candidates have been proposed but have not yet reached clinical requirements, which is predominantly due to the fact that the majority of studies are based on a single candidate gene (34-38). For example, methylated $C D K N 2 A$, commonly referred to as p16, was an early focus in the search for diagnostic biomarkers in lung cancer plasma; however, although earlier studies identified $C D K N 2 A$ promoter methylation in the plasma of patients with lung cancer (39-42), subsequent studies have described low sensitivity and specificity of this method $(32,43,44)$. Methylated plasma $C D K N 2 A$ may be used to detect lung cancer; however, it is more likely to be used as one part of a biomarker panel rather than as a single gene diagnostic marker. Other candidate genes include adenomatous polyposis coli $(45,46)$, ras association domain family $1 \mathrm{~A}$ gene $(34,43,44,46,47)$, retinoic acid receptor $\beta(43,44,46,48)$ and cadherin $13(43,44,46)$; however, the sensitivity of these genes is generally low. The diagnostic firm Theracode identified short stature homeobox protein 2 as a potential biomarker (49); however, only $60 \%$ sensitivity (95\% confidence interval, 53-67\%) and 90\% specificity (95\% confidence interval, 84-94\%) were identified (49). A multigene panel is a viable solution to the sensitivity and specificity concerns; however, more candidate genes need to be identified. Another consideration is that if early diagnosis of lung cancer requires a panel approach to assess plasma circulating tumor DNA, a panel with tumor type specificity is required, which requires a single gene methylation change in the panel or a combination of gene methylation changes indicating lung cancer. The present study demonstrated that PTTGIIP may be a new and specific gene that is aberrantly methylated in lung cancer.

PTTG1IP, also termed PBF, was originally reported to bind and promote the nuclear translocation of PTTG1 (50). PTTG1 is a marker of invasive colorectal cancer (51) and is a key signature gene associated with tumor metastasis (52). The functional interaction between PTTG1 and p53 has been demonstrated in transformed cells $(53,54)$.

A number of studies have suggested that the subcellular localization of PTTG1IP and PTTG1 is crucial for progression of mitosis through the metaphase-anaphase transition $(14,15,18)$. PTTG1IP promotes PTTG1 activation by promoting transfer of PTTG1 from the cytoplasm to the nucleus, thereby allowing the interaction between separase and PTTG1 (50). In addition to its role in metaphase/anaphase transition, PTTG1IP is also involved in transactivation of fibroblast growth factor 2 (50) and regulation of the human symporter in thyroid cells through its interaction with PTTG1 (55). However, to date, the full functionality of PTTG1IP has not been revealed.

PTTG1IP overexpression has been previously observed in certain types of malignancy, including thyroid (25), breast (53) and colorectal (52) cancer. However, to the best of our knowledge, PTTG1IP expression in other cancer types, including lung cancer, has not been reported. Expression data for all genes in lung adenocarcinoma, breast cancer, colorectal cancer, kidney cancer, melanoma, liver cancer and ovarian cancer (GSE1007, GSE20347, GSE32323, GSE6344, GSE3189, GSE14520 and GSE14407) were downloaded from the Gene Expression Omnibus database in NCBI. The ID REF for PTTG1IP is 200677_at. The results of the analysis demonstrated that expression changes were not consistent among the tumor types, suggesting that PTTGIIP may perform different roles in different tumors (data not shown). Furthermore, it was revealed that the expression of PTTGIIP was regulated by the DNA methylation level. Further investigation demonstrated that DNA methylation at the shore of the CGI in the promoter region was negatively associated with PTTGIIP expression. More importantly, this region was hypermethylated in early-stage NSCLC. An appropriate gene methylation marker for early diagnosis of lung cancer may be a lung cancer-specific hypermethylated DNA site. Therefore, the unique performance of PTTGIIP in early-stage NSCLC suggests it can be used as an early biomarker for lung cancer diagnosis. Of course, prior to application in the clinic, further investigations are required to verify whether hypermethylation of the PTTGIIP promoter can be detected in body fluids, including sputum and plasma, from patients with early-stage NSCLC.

In conclusion, to the best of our knowledge, the present study investigated the expression of PTTGIIP in early-stage lung cancer for the first time. Low expression and promoter hypermethylation were identified. Furthermore, a negative correlation between PTTGIIP expression and methylation levels was revealed. These findings indicate that the methylation level of the PTTGIIP promoter region may be a candidate biomarker for early diagnosis of lung cancer.

\section{Acknowledgements}

Not applicable.

\section{Funding}

The present study was supported by The National Natural Science Foundation of China (grant no. 81872103 and no. 81372768), Natural Science Foundation of Minhang District (grant no. 2015MHZ069), Training Program of Renji Hospital (grant no. 2017PYQA09) and the Science and Technology Climbing Fund of SIPPR (grant nos. PD2017-2 and PD2017-4).

\section{Availability of data and materials}

The datasets used and/or analyzed during the present study are available from the corresponding author on reasonable request.

\section{Authors' contributions}

XT and HJ provided the samples. XT, SZ and HG performed the experiments. WH, MX and QW analyzed the data. XT and QW wrote the manuscript. XN and HJ designed and supervised the study and wrote the manuscript. 


\section{Ethics approval and consent to participate}

All experimental protocols were approved by the Ethics Committee of South Hospital of Renji Hospital Shanghai Jiao Tong University School of Medicine (Shanghai, China). Written informed consent was obtained from each patient prior to participation.

\section{Patient consent for publication}

Not applicable.

\section{Competing interests}

The authors declare that they have no competing interests.

\section{References}

1. Torre LA, Bray F, Siegel RL, Ferlay J, Lortet-Tieulent J and Jemal A: Global cancer statistics, 2012. CA Cancer J Clin 65: 87-108, 2015.

2. Siegel RL, Miller KD and Jemal A: Cancer statistics, 2017. CA Cancer J Clin 67: 7-30, 2017.

3. Anglim PP, Alonzo TA and Laird-Offringa IA: DNA methylation-based biomarkers for early detection of non-small cell lung cancer: An update. Mol Cancer 7: 81, 2008.

4. Guo S, Yan F, Xu J, Bao Y, Zhu J, Wang X, Wu J, Li Y, $\mathrm{Pu} \mathrm{W}$, Liu Y, et al: Identification and validation of the methylation biomarkers of non-small cell lung cancer (NSCLC). Clin Epigenetics 7: 3, 2015.

5. Sardi AH and Islam S: Early lung cancer detection, mucosal, and alveolar imaging. Curr Opin Pulm Med 22: 271-280, 2016.

6. Yang IV and Schwartz DA: Epigenetic control of gene expression in the lung. Am J Respir Crit Care Med 183: 1295-1301, 2011.

7. Belinsky SA: Gene-promoter hypermethylation as a biomarker in lung cancer. Nat Rev Cancer 4: 707-717, 2004.

8. Ooki A, Maleki Z, Tsay JJ, Goparaju C, Brait M, Turaga N, Nam HS, Rom WN, Pass HI, Sidransky D, et al: A panel of novel detection and prognostic methylated DNA markers in primary non-small cell lung cancer and serum DNA. Clin Cancer Res 23: 7141-7152, 2017.

9. Walter K, Holcomb T, Januario T, Yauch RL, Du P, Bourgon R, Seshagiri S, Amler LC, Hampton GM and S Shames D: Discovery and development of DNA methylation-based biomarkers for lung cancer. Epigenomics 6: 59-72, 2014.

10. Bedford MT and van Helden PD: Hypomethylation of DNA in pathological conditions of the human prostate. Cancer Res 47: 5274-5276, 1987.

11. Portela A, Liz J, Nogales V, Setién F, Villanueva A and Esteller M: DNA methylation determines nucleosome occupancy in the 5'-CpG islands of tumor suppressor genes. Oncogene 32: 5421-5428, 2013.

12. Hao X, Luo H, Krawczyk M, Wei W, Wang W, Wang J, Flagg K, Hou J, Zhang H, Yi S, et al: DNA methylation markers for diagnosis and prognosis of common cancers. Proc Natl Acad Sci USA 114: 7414-7419, 2017.

13. Herman JG and Baylin SB: Gene silencing in cancer in association with promoter hypermethylation. N Engl J Med 349: 2042-2054, 2003.

14. Read ML, Seed RI, Fong JC, Modasia B, Ryan GA, Watkins RJ, Gagliano T, Smith VE, Stratford AL, Kwan PK, et al: The PTTG1-binding factor (PBF/PTTG1IP) regulates p53 activity in thyroid cells. Endocrinology 155: 1222-1234, 2014.

15. Imruetaicharoenchoke W, Fletcher A, Lu W, Watkins RJ, Modasia B, Poole VL, Nieto HR, Thompson RJ, Boelaert K, Read ML, et al: Functional consequences of the first reported mutations of the proto-oncogene PTTG1IP/PBF. Endocr Relat Cancer 24: 459-474, 2017.

16. Stratford AL, Boelaert K, Tannahill LA, Kim DS, Warfield A, Eggo MC, Gittoes NJ, Young LS, Franklyn JA and McCabe CJ: Pituitary tumor transforming gene binding factor: A novel transforming gene in thyroid tumorigenesis. J Clin Endocrinol Metab 90: 4341-4349, 2005.

17. Watkins RJ, Read ML, Smith VE, Sharma N, Reynolds GM, Buckley L, Doig C, Campbell MJ, Lewy G, Eggo MC, et al: Pituitary tumor transforming gene binding factor: A new gene in breast cancer. Cancer Res 70: 3739-3749, 2010.
18. Read ML, Seed RI, Modasia B, Kwan PP, Sharma N, Smith VE, Watkins RJ, Bansal S, Gagliano T, Stratford AL, et al: The proto-oncogene PBF binds p53 and is associated with prognostic features in colorectal cancer. Mol Carcinog 55: 15-26, 2016.

19. Li C, Wang Y, Wang S, Wu B, Hao J, Fan H, Ju Y, Ding Y, Chen L, Chu X, et al: Hepatitis B virus mRNA-mediated miR-122 inhibition upregulates PTTG1-binding protein, which promotes hepatocellular carcinoma tumor growth and cell invasion. J Virol 87: 2193-2205, 2013.

20. Edge SB and Compton CC: The American Joint Committee on Cancer: The 7th edition of the AJCC cancer staging manual and the future of TNM. Ann Surg Oncol 17: 1471-1474, 2010.

21. Livak KJ and Schmittgen TD: Analysis of relative gene expression data using real-time quantitative PCR and the 2(-Delta Delta C(T)) method. Methods 25: 402-408, 2001.

22. Gu H, , Bock C, Boyle P, Gnirke A and Meissner A: Preparation of reduced representation bisulfite sequencing libraries for genome-scale DNA methylation profiling. Nat Protoc 6: 468-481, 2011.

23. Akalin A, Kormaksson M, Li S, Garrett-Bakelman FE, Figueroa ME, Melnick A and Mason CE: methylKit: A comprehensive $R$ package for the analysis of genome-wide DNA methylation profiles. Genome Biol 13: R87, 2012.

24. R Core Team: R: A language and environment for statistical. computing. R Foundation for Statistical Computing, Vienna, Austria, 2013.

25. Hsueh C, Lin JD, Chang YS, Hsueh S, Chao TC, Yu JS, Jung SM, Tseng NM, Sun JH, Kuo SY and Ueng SH: Prognostic significance of pituitary tumour-transforming gene-binding factor (PBF) expression in papillary thyroid carcinoma. Clin Endocrinol (Oxf) 78: 303-309, 2013.

26. National Lung Screening Trial Research Team, Aberle DR, Adams AM, Berg CD, Black WC, Clapp JD, Fagerstrom RM, Gareen IF, Gatsonis C, Marcus PM and Sicks JD: Reduced lung-cancer mortality with low-dose computed tomographic screening. N Engl J Med 365: 395-409, 2011.

27. Tammemägi MC, Katki HA, Hocking WG, Church TR, Caporaso N, Kvale PA, Chaturvedi AK, Silvestri GA, Riley TL, Commins J and Berg CD: Selection criteria for lung-cancer screening. N Engl J Med 368: 728-736, 2013.

28. Brock MV, Hooker CM, Ota-Machida E, Han Y, Guo M, Ames S, Glöckner S, Piantadosi S, Gabrielson E, Pridham G, et al: DNA methylation markers and early recurrence in stage I lung cancer. N Engl J Med 358: 1118-1128, 2008.

29. Leng S, Do K, Yingling CM, Picchi MA, Wolf HJ, Kennedy TC, Feser WJ, Baron AE, Franklin WA, Brock MV, et al: Defining a gene promoter methylation signature in sputum for lung cancer risk assessment. Clin Cancer Res 18: 3387-3395, 2012.

30. Sandoval J, Mendez-Gonzalez J, Nadal E, Chen G, Carmona FJ, Sayols S, Moran S, Heyn H, Vizoso M, Gomez A, et al: A prognostic DNA methylation signature for stage I non-small-cell lung cancer. J Clin Oncol 31: 4140-4147, 2013.

31. Yang X, Dai W, Kwong DL, Szeto CY, Wong EH, Ng WT, Lee AW, Ngan RK, Yau CC, Tung SY, et al: Epigenetic markers for noninvasive early detection of nasopharyngeal carcinoma by methylation-sensitive high resolution melting. Int J Cancer 136: E127-E135, 2015.

32. Heyn $\mathrm{H}$ and Esteller M: DNA methylation profiling in the clinic: Applications and challenges. Nat Rev Genet 13: 679-692, 2012.

33. Vogelstein B, Papadopoulos N, Velculescu VE, Zhou S, Diaz LA Jr and Kinzler KW: Cancer genome landscapes. Science 339: 1546-1558, 2013.

34. Belinsky SA, Klinge DM, Dekker JD, Smith MW, Bocklage TJ, Gilliland FD, Crowell RE, Karp DD, Stidley CA and Picchi MA: Gene promoter methylation in plasma and sputum increases with lung cancer risk. Clin Cancer Res 11: 6505-6511, 2005.

35. Topaloglu O, Hoque MO, Tokumaru Y, Lee J, Ratovitski E, Sidransky D and Moon CS: Detection of promoter hypermethylation of multiple genes in the tumor and bronchoalveolar lavage of patients with lung cancer. Clin Cancer Res 10: 2284-2288, 2004.

36. Geng J, Sun J, Lin Q, Gu J, Zhao Y, Zhang H, Feng X, He Y, Wang W, Zhou X and Yu J: Methylation status of NEUROG2 and NID2 improves the diagnosis of stage I NSCLC. Oncol Lett 3: 901-906, 2012.

37. Schmidt B, Liebenberg V, Dietrich D, Schlegel T, Kneip C, Seegebarth A, Flemming N, Seemann S, Distler J, Lewin J, et al: SHOX2 DNA methylation is a biomarker for the diagnosis of lung cancer based on bronchial aspirates. BMC Cancer 10: 600, 2010 . 
38. Nikolaidis G, Raji OY, Markopoulou S, Gosney JR, Bryan J, Warburton C, Walshaw M, Sheard J, Field JK and Liloglou T: DNA methylation biomarkers offer improved diagnostic efficiency in lung cancer. Cancer Res 72: 5692-5701, 2012.

39. Bearzatto A, Conte D, Frattini M, Zaffaroni N, Andriani F, Balestra D, Tavecchio L, Daidone MG and Sozzi G: p16(INK4A) Hypermethylation detected by fluorescent methylation-specific PCR in plasmas from non-small cell lung cancer. Clin Cancer Res 8: 3782-3787, 2002.

40. Kurakawa E, Shimamoto T, Utsumi K, Hirano T, Kato H and Ohyashiki K: Hypermethylation of p16(INK4a) and p15(INK4b) genes in non-small cell lung cancer. Int J Oncol 19: 277-281, 2001

41. An Q, Liu Y, Gao Y, Huang J, Fong X, Li L, Zhang D and Cheng S: Detection of p16 hypermethylation in circulating plasma DNA of non-small cell lung cancer patients. Cancer Lett 188: 109-114, 2002

42. Ng CS, Zhang J, Wan S, Lee TW, Arifi AA, Mok T, Lo DY and Yim AP: Tumor p16M is a possible marker of advanced stage in non-small cell lung cancer. J Surg Oncol 79: 101-106, 2002.

43. Hsu HS, Chen TP, Hung CH, Wen CK, Lin RK, Lee HC and Wang YC: Characterization of a multiple epigenetic marker panel for lung cancer detection and risk assessment in plasma. Cancer 110: 2019-2026, 2007.

44. Wang YC, Hsu HS, Chen TP and Chen JT: Molecular diagnostic markers for lung cancer in sputum and plasma. Ann N Y Acad Sci 1075: 179-184, 2006.

45. Usadel H, Brabender J, Danenberg KD, Jerónimo C, Harden S, Engles J, Danenberg PV, Yang S and Sidransky D: Quantitative adenomatous polyposis coli promoter methylation analysis in tumor tissue, serum and plasma DNA of patients with lung cancer. Cancer Res 62: 371-375, 2002.

46. Rykova EY, Skvortsova TE, Laktionov PP, Tamkovich SN, Bryzgunova OE, Starikov AV, Kuznetsova NP, Kolomiets SA, Sevostianova NV and Vlassov VV: Investigation of tumor-derived extracellular DNA in blood of cancer patients by methylation-specific PCR. Nucleosides Nucleotides Nucleic Acids 23: 855-859, 2004.

47. Ponomaryova AA, Rykova EY, Cherdyntseva NV, Skvortsova TE Dobrodeev AY, Zav'yalov AA, Tuzikov SA, Vlassov VV and Laktionov PP: RAR $\beta 2$ gene methylation level in the circulating DNA from blood of patients with lung cancer. Eur J Cancer Prev 20: 453-455, 2011.
48. Ponomaryova AA, Rykova EY, Cherdyntseva NV, Skvortsova TE, Dobrodeev AY, Zav'yalov AA, Bryzgalov LO, Tuzikov SA, Vlassov VV and Laktionov PP: Potentialities of aberrantly methylated circulating DNA for diagnostics and post-treatment follow-up of lung cancer patients. Lung Cancer 81: 397-403, 2013.

49. Kneip C, Schmidt B, Seegebarth A, Weickmann S Fleischhacker M, Liebenberg V, Field JK and Dietrich D: SHOX2 DNA methylation is a biomarker for the diagnosis of lung cancer in plasma. J Thorac Oncol 6: 1632-1638, 2011.

50. Chien W and Pei L: A novel binding factor facilitates nuclear translocation and transcriptional activation function of the pituitary tumor-transforming gene product. J Biol Chem 275: 19422-19427, 2000.

51. Heaney AP, Singson R, McCabe CJ, Nelson V, Nakashima M and Melmed S: Expression of pituitary-tumour transforming gene in colorectal tumours. Lancet 355: 716-719, 2000.

52. Carvalho L, Yu J, Schwartsmann G, McLeod HL and Fleshman JW: RNA expression of the molecular signature genes for metastasis in colorectal cancer. Oncol Rep 25: 1321-1327, 2011.

53. Bernal JA, Luna R, Espina A, Lázaro I, Ramos-Morales F, Romero F, Arias C, Silva A, Tortolero M and Pintor-Toro JA: Human securin interacts with p53 and modulates p53-mediated transcriptional activity and apoptosis. Nat Genet 32: 306-311, 2002.

54. Kim DS, Fong J, Read ML and McCabe CJ: The emerging role of pituitary tumour transforming gene (PTTG) in endocrine tumourigenesis. Mol Cell Endocrinol 278: 1-6, 2007.

55. Boelaert K, Smith VE, Stratford AL, Kogai T, Tannahill LA, Watkinson JC, Eggo MC, Franklyn JA and McCabe CJ: PTTG and PBF repress the human sodium iodide symporter. Oncogene 26: 4344-4356, 2007.

This work is licensed under a Creative Commons Attribution-NonCommercial-NoDerivatives 4.0 International (CC BY-NC-ND 4.0) License. 